\title{
Aetiology of bipolar disorder: contribution of the L-type voltage-gated calcium channels
}

\author{
Xiaoyun Guo, ${ }^{1}$ Dengtang Liu, ${ }^{2}$ Tong Wang, ${ }^{3}$ Xingguang Luo ${ }^{4}$
}

\section{LTCCS ARE IMPLICATED IN THE PATHOLOGY OF BIPOLAR DISORDER}

Bipolar disorder (BPD) is a common mental illness with significant morbidity and mortality. ${ }^{1}$ Although evidence have suggested changes in oxidative stress, dopamine and inflammation in BPD, it is hard to define the aetiological mechanism of BPD clearly. Recently, some but not all candidate gene association studies, family-based association studies, linkage studies, genome-wide association studies (GWASs) and meta-analyses showed that mutation of L-type voltage-gated calcium channels (LTCCs) gene CACNA1C is implicated in the mechanism of BPD. ${ }^{2-8}$ These findings support the possibility that BPD might have calcium channelopathy. ${ }^{9}$

LTCCs, which consist of a complex of alpha-1, alpha-2/delta and beta subunits in a 1:1:1 ratio, mediate the influx of calcium ions $\left(\mathrm{Ca}^{2+}\right)$ into the cell on membrane polarization. The alpha-1 subunit consists of 24 transmembrane segments and forms the pore through which ions pass into the cell. Cav1.2 is crucial in modulating kinetics of the LTCCs. ${ }^{10}$ Cav1.2 is widely expressed in the heart ${ }^{11} 12$ and brain. ${ }^{13}$ So far, it is well known for its function in the heart. ${ }^{11} 12$ LTCCs are located at both presynaptic nerve terminals and postsynaptic dendrites and dendritic spines. It initiates many

\footnotetext{
${ }^{1}$ Department of psychiatry, Shanghai Mental Health Center, Shanghai, China

${ }^{2}$ Department of psychiatry, Shanghai Mental Health Center, Shanghai, China

${ }^{3}$ Department of Cellular and Molecular Physiology, Yale University School of Medicine, New Haven, Connecticut, USA

${ }^{4}$ Department of Psychiatry, Yale University School of Medicine, New Haven, Connecticut, USA
}

Correspondence to Dr Xiaoyun Guo, Shanghai, China; xiaoyunguo@163.comDr Dengtang Liu; erliu110@126.com physiological responses, including secretion, muscle contraction and gene transcription.

LTCCs have prominent roles in learning and memory processes, which might be related with the pathology of BPD. ${ }^{14}$ LTCCs might control gene expression through coupling membrane depolarisation with cAMP response element-binding protein (CREB) phosphorylation via local $\mathrm{Ca}^{2+} /$ calmodulin-dependent protein kinase II (CaMKII) signalling. ${ }^{15}$ This pathway and particularly CREB and BDNF are thought to be essential for learning and memory processes. Cav1.2 knockdown models have shown reduced CREB transcription and hippocampal $\mathrm{LTP}^{16}$ implicating the importance of these channels in learning and memory process.

LTCCs appear to be particularly important for the normal function of dopaminergic $^{17}$ and 5-serotonergic ${ }^{18}$ neuron function in the frontal cortex and mesolimbic dopamine systems, which contribute to the aetiology of BPD and might be correlated with LTCCs function. Because homozygous deletion of CACNA1C is lethal, the heterozygous CACNA1C knockout (HET) mouse was used for sleeping disorder ${ }^{19}$ and mood-related behaviour studies. ${ }^{20}$ CACNA1C heterozygous haploinsufficient mice manifested an attenuated response to the specific dopamine uptake inhibitor GBR12909, indicating that LTCCs critically regulated dopaminergic terminal function. ${ }^{17}$

The efficacy of the LTCCs blocker verapamil might alleviate acute mania in BPD, ${ }^{21}$ while several others report no antimanic effects when verapamil was administered as a monotherapy. ${ }^{22} 23$ It is reported that when verapamil was administered in combination with the mood stabiliser lithium to patients who were unresponsive to lithium, ${ }^{24}$ there was significant improvement in manic symptoms.

Interestingly, the current research has showed LTCCs might be associated with the treatment response to the effect of antipsychotics in schizophrenia. Yu and colleagues ${ }^{25}$ examined treatment response on LTCCs in patients with schizophrenia. They examined 2413 patients, together with a validation cohort of 1379 patients, and found that the rs2239063 in CACNA1C was associated with treatment response to olanzapine. Actually, psychiatrists often see patients with a mixture of manic and schizophrenic symptoms. Sometimes it is difficult to determine whether a patient has schizophrenia or BPD. We speculated that the same spectrum of genes might contribute to the causes of both BPD and schizophrenia.

\section{CONTRADICTORY EVIDENCE FOR THE RELATIONSHIP BETWEEN LTCCS AND BIPOLAR DISORDER}

Although many reports showed the association between CACNA1C and $\mathrm{BPD},{ }^{2-8}$ the SNP was not well replicated among the published GWASs. Khalid and colleagues ${ }^{26}$ research showed that rs1006737 in CACNA1C has emerged as the most highly replicable SNP significantly associated with BPD. In their study, a total of 120 BPD and 120 control individuals from Pakistan were examined. ${ }^{26} \mathrm{Kim}$ and colleagues, $^{27}$ research showed that two other CACNA1C SNPs, namely rs723672 and rs1051375, were associated with BPD while examining 287 Korean patients and 340 healthy controls.

\section{CONCLUSIONS}

Although accumulated reports showed the association between CACNA1C and BPD, the result was not well replicated among the public GWASs. The mechanisms of how genetic alterations in LTCCs affect the risk for BPD remain unknown. According to the current published 
research, LTCCs might be related with the monoaminergic signal pathway via the frontal cortex and mesolimbic systems. The brain-region-specific influence of CACNA1C risk SNPs on mania symptoms should be addressed. Neuroimaging, including MRI and fMRI studies, would be excellent methods to examine the brain-region-specific morphology and function in vivo. Future research should also focus on molecular neural circuit studies in animal models or in vitro studies about LTCCs function, especially neuroinflammation and neurotrophy function, which contribute critically to the aetiology of BPD. Second, based on the previous neurobiological results, we need to find more evidence of LTCCs for the differential diagnosis of major psychiatric disease as well. We might also identify biological pathways underlying specific shared or unique symptoms for the major psychiatric disease. Finally, more randomised placebo-controlled clinical studies should be carried out to confirm the clinical effect of calcium channel-targeted medicine (eg, LTCCs blocker) on BPD. Molecular mechanism of mood stabilisers targeted to calcium channels, especially LTCCs blocker, might also be well addressed in the future. We are looking forward for the further understanding of the LTCCs which may provide a breakthrough for the aetiological and pathogenetic research of BPD. Hopefully scientists and pharmacological companies will work together to develop more potentially safe and effective new drugs based on LTCCs in the future.

Correction notice This article has been corrected since it was first published. This article was not published under an Open Access licence. This has now been corrected.

Acknowledgements We appreciate Professor Kaida Jiang who reviewed and gave comments for this article.

Contributors XG wrote the article. DL, TW and XL reviewed and revised the article.

Funding This study is funded by the National Natural Science Foundation of China (81201057), Shanghai Municipal Health Bureau Project (20124109), Chinese Medical Association, Psychiatry-Servier Youth Research Fund, Shanghai Mental Health Center International Cooperation Project (2013-) and Shanghai Municipal Center for Mental Health Clinical Research Program.
Competing interests None declared.

Patient consent for publication Not required.

Provenance and peer review Not commissioned; externally peer reviewed.

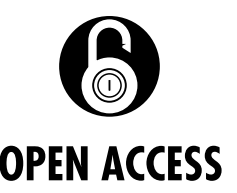

Open access This is an open access article distributed in accordance with the Creative Commons Attribution Non Commercial (CC BY-NC 4.0) license, which permits others to distribute, remix, adapt, build upon this work non-commercially, and license their derivative works on different terms, provided the original work is properly cited, appropriate credit is given, any changes made indicated, and the use is non-commercial. See: http://creativecommons.org/licenses/by-nc/4.0/.

(c) Author(s) (or their employer(s)) 2019. Re-use permitted under CC BY-NC. No commercial re-use. See rights and permissions. Published by BMJ.

\section{Check for updates}

To cite Guo X, Liu D, Wang T, et al. General Psychiatry Epub ahead of print: [please include Day Month Year]. doi:10.1136/gpsych-2018-100009

Received 30 August 2018

Revised 24 February 2019

Accepted 19 March 2019

General Psychiatry 2019;32:e100009.

doi:10.1136/gpsych-2018-100009

\section{REFERENCES}

1 Yatham LN, Kennedy SH, Parikh SV, et al. Canadian Network for Mood and Anxiety Treatments (CANMAT) and International Society for Bipolar Disorders (ISBD) 2018 guidelines for the management of patients with bipolar disorder. Bipolar Disord 2018;20:97-170.

2 Sklar P, Smoller JW, Fan J, et al. Wholegenome association study of bipolar disorder. Mol Psychiatry 2008;13:558-69.

3 Schizophrenia Psychiatric Genome-Wide Association Study (GWAS) Consortium. Genome-wide association study identifies five new schizophrenia loci. Nat Genet 2011;43:969-76.

4 Liu Y, Blackwood DH, Caesar S, et al. Meta-analysis of genome-wide association data of bipolar disorder and major depressive disorder. Mol Psychiatry 2011;16:2-4.

5 Ferreira MAR, O'Donovan MC, Meng YA, et al. Collaborative genome-wide association analysis supports a role for ANK3 and CACNA1C in bipolar disorder. Nat Genet 2008:40:1056-8.

6 Ruderfer DM, Fanous AH, Ripke S, et al. Polygenic dissection of diagnosis and clinical dimensions of bipolar disorder and schizophrenia. Mol Psychiatry 2014;19:1017-24.

7 Psychiatric GWAS Consortium Bipolar Disorder Working Group. Large-scale genome-wide association analysis of bipolar disorder identifies a new susceptibility locus near Odz4. Nat Genet 2011;43:977-83.

8 Schizophrenia Working Group of the Psychiatric Genomics Consortium. Biological insights from 108 schizophreniaassociated genetic loci. Nature 2014;511:421-7.

9 Harrison PJ, Geddes JR, Tunbridge EM. The emerging neurobiology of bipolar disorder. Trends Neurosci 2018;41:18-30.

10 Lipscombe D, Helton TD, Xu W. L-type calcium channels: the low down. $J$ Neurophysiol 2004;92:2633-41.

11 Wemhöner K, Friedrich C, Stallmeyer B, et al. Gain-of-function mutations in the calcium channel CACNA1C (CaV1.2) cause non-syndromic long-QT but not Timothy syndrome. J Mol Cell Cardiol 2015;80:186-95.

12 Chen Y, Barajas-Martinez H, Zhu D, et al. Novel trigenic CACNA1C/DES/MYPN mutations in a family of hypertrophic cardiomyopathy with early repolarization and short QT syndrome. J Trans/ Med 2017;15.

13 Berger SM, Bartsch D. The role of L-type voltage-gated calcium channels Cav1.2 and Cav1.3 in normal and pathological brain function. Cell Tissue Res 2014;357:463-76.

14 Moon AL, Haan N, Wilkinson LS, et al. CACNA1C: association with psychiatric disorders, behavior, and neurogenesis. Schizophr Bull 2018;44:958-65.

15 Wheeler DG, Groth RD, Ma H, et al. Ca(V)1 and $\mathrm{Ca}(\mathrm{V}) 2$ channels engage distinct modes of $\mathrm{Ca}(2+)$ signaling to control CREB-dependent gene expression. Cell 2012;149:1112-24.

16 Moosmang S, Haider N, Klugbauer N, et al. Role of hippocampal Cav1.2 Ca2+ channels in NMDA receptor-independent synaptic plasticity and spatial memory. $J$ Neurosci 2005;25): :9883-92.

17 Terrillion CE, Dao DT, Cachope R, et al. Reduced levels of Cacna1c attenuate mesolimbic dopamine system function. Genes Brain Behav 2017;16:495-505.

18 Colgan LA, Cavolo SL, Commons KG, et al. Action potential-independent and pharmacologically unique vesicular serotonin release from dendrites. $J$ Neurosci 2012;32:15737-46.

19 Kumar D, Dedic N, Flachskamm C, et al. Cacna1c (CaV1.2) modulates electroencephalographic rhythm and rapid eye movement sleep recovery. Sleep 2015;38:1371-80.

20 Dao DT, Mahon PB, Cai X, et al. Mood disorder susceptibility gene CACNA1C modifies mood-related behaviors in mice and interacts with sex to influence behavior in mice and diagnosis in humans. Biol Psychiatry 2010;68:801-10.

21 Cipriani A, Saunders K, Attenburrow $\mathrm{M}-\mathrm{J}$, et al. A systematic review of calcium channel antagonists in bipolar disorder and some considerations for their future development. Mol Psychiatry 2016;21:1324-32.

22 Lenzi A, Marazziti D, Raffaelli S, et al. Effectiveness of the combination verapamil and chlorpromazine in the treatment of severe manic or mixed patients. Prog Neuropsychopharmacol Biol Psychiatry 1995;19:519-28.

23 Barton BM, Gitlin MJ. Verapamil in treatment-resistant mania: an open trial. $J$ Clin Psychopharmacol 1987;7:101-3.

24 Mallinger AG, Thase ME, Haskett $\mathrm{R}$, et al. Verapamil augmentation of lithium treatment improves outcome in 
mania unresponsive to lithium alone: preliminary findings and a discussion of therapeutic mechanisms. Bipolar Disord 2008;10:856-66.

25 Yu H, Yan H, Wang L, et al. Five novel loci associated with antipsychotic treatment response in patients with schizophrenia: a genome-wide association study. Lancet Psychiatry 2018;5:327-38.

26 Khalid M, Driessen TM, Lee JS, et al. Association of CACNA1C with bipolar disorder among the Pakistani population. Gene 2018;664:119-26.

$27 \mathrm{Kim} \mathrm{S}$, Cho C-H, Geum D, et al. Association of CACNA1C variants with bipolar disorder in the Korean population. Psychiatry Investig 2016;13:453-7.

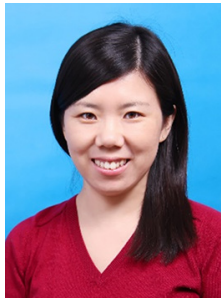

Dr. Xiaoyun Guo obtained a Degree of Medicine in 2001, a Master Degree in Psychiatry in 2004, and a PhD in Psychiatry (Fudan University) in 2007. She has been working at Shanghai Mental Health Center since 2007. Currently, she works as the Associate Chief Physician in Shanghai Mental Health Center. Her research interest focuses on the genetic and immunological mechanism of major psychiatric disorders. 